\title{
NILAI-NILAI PENDIDIKAN ISLAM DALAM TRADISI MERTI DESO DI DESA SUKU MENANTI REJANG LEBONG, BENGKULU
}

\author{
Dedik Prianto \\ Institut A gama Islam Negeri Curup B engkulu \\ dedikprianto12@gmail.com \\ Lukman A sha \\ Institut A gama Islam Negeri Curup B engkulu \\ Guntur Putra J aya \\ Institut A gama Islam Negeri Curup B engkulu
}

\begin{abstract}
A bstract
This study aimed at finding out Islamic education values embedded in the tradition of Merti Deso in Suku Menanti Village, Sindang Jati District, Rejang Lebong Regency, Bengkulu. This study used a descriptive qualitative approach. The data collection techniques used in this study encompassed observation and interviews conducted periodically. A fter the data were collected, the data were further analyzed by means of Miles, Haberman, and Saldana's version of stages, namely data selection, data presentation, and drawing conclusion. This study concluded that the Islamic education values embedded in the tradition of M erti Deso were First, religious and spiritual values, such as an expression of gratitude to God A Imighty who has given so much fortune over the course of one year and praying to avoid disaster and disasters in the future. Second, the social value which is proven by the M erti Deso activities running smoothly because of the strong relationships and high attitudes of mutual cooperation without distinguishing religion and belief, social status and others. Third, Economic Value, a series of activities in M erti Deso make many residents gather so as to provide business opportunities for residents and this directly provides economic benefits for residents.
\end{abstract}

Keywords: Islamic Education Values, Merti Deso Tradition 


\begin{abstract}
A bstrak
Penelitian ini bertujuan menemukan nilai-nilai pendidikan Islam yang terkandung dala tradisi merti deso di Desa Suku M enanti, Kecamatan Sindang Jati Kabupaten Rejang Lebong, Bengkulu. Penelitian ini menggunakan pendekatan kualitatif deskriptif. A dapun teknik pengumpul data yang digunakan dalam penelitian ini adalah observasi dan warancara secara berkala. Setelah data terkumpul Ialu dianalisis dengan tahapan versi M iles, Haberman dan Saldana yaitu pemilihan data, penyajian dan penarikan kesimpulan. Penelitian ini memperoleh simpulan bahwa nilai-nilai pendidikan Islam yang terdapat pada tradisi merti deso yaitu: Pertama, nilai Religius dan spiritual, seperti ungkapan rasa syukur kepada Tuhan yang $M$ aha Esa yang telah memberikan begitu banyak limpahan rejeki selama satu tahun tersebut dan berdoa agar terhindar dari bala dan bencana di masa yang akan datang. Kedua, nilai Sosial yang buktikan dengan kegiatan M erti Deso berjalan dengan lancar karena jalinan silaturrahim yang kuat dan sikap gotong Royong yang tinggi tanpa membedakan agama dan keyakinan, status social dan lain-lain. Ketiga, Nilai Ekonomi, rangkaian kegiatan dalam M erti Deso banyak membuat warga berkumpul sehungga memberikan peluang usaha bagi warga dan hal ini secara langsung memberikan keuntungan ekonomi bagi warga.
\end{abstract}

Kata kunci: Nilai Pendidikan Islam, Tradisi M erti Deso 


\section{PENDAHULUAN}

Masyarakat adalah objek utama dalam kebudayaan, terdapat banyak sekali macam-macam kebudayaan yang ada dunia ini ${ }^{1}$. Kebudayaan sendiri diartikan sebagai hasil cita, cipta, karya dan karsa manusia yang diperoleh melalui belajar². Jika ditinjau konteks R ejang L ebong yang terdiri dari suku yang sangat heterogen tentu diikuti oleh adat istiadat yang beragam, baik itu yang berasal dari suku asli Rejang Lebong maupun yang dibawa oleh pendatang dari luar daerah seperti suku Jawa, Sunda, Minang, Batak dan lain-lain ${ }^{3}$. A dat istiadat dimaksud termasuk tradisi budaya yang secara turun temurun diwariskan dan masih dilestarikan hingga saat ini.

Secara terminologis adat istiadat merupakan aturan dan perbuatan yang selalu diikuti oleh sebuah suku yang telah berlangsung sejak lama, dijaga dan dipelihara dari generasi ke generasi dalam suatu masyarakat ${ }^{4}$. Beberapa tradisi masih membudaya di wilayah Kabupaten Rejang Lebong misalnya: suroan, kenduri/kendoren, umbung, narhaban dan lain sebagainya. Pelestarian budaya tersebut menunjukkan bahwa kebudayaan, tradis atau adat istiadat masih dipengan teguh oleh masyarakat Rejeng Lebong dalam kehidupannya sehari-hari.

Sebelum lebih jauh membahas tentang tradisi yang masih dilestatarikan di Rejang Lebong, perlu dipahami bahwa istilah kebudayaan berasal dari bahasa sansekerta yang

1 Emi Wakhyuni, "Kemampuan Masyarakat dan Budaya Asing dalam Mempertahankan Budaya Lokal di Kecamatan Datuk Bandar," Jurnal Abdi Ilmu 11, no. 1 (2018): 25-31; Alim Puspianto, "Tantangan Dakwah Antar Budaya di Media Massa," An-Nida': Jurnal Komunikasi Dan Penyiaran Islam 6, no. 1 (2017): 25-46.

2 Nurhasanah Nurhasanah, "Faktor-Faktor Penyebab Rendahnya Prestasi Belajar Aqidah Akhlak Di Kelas IV MIS Iqro' Ummat Kecamatan Manggelewa Tahun Pelajaran 2016/2017," AL-FURQAN 5, no. 1 (2016): 1540 .

3 Idi Warsah, Dewi Cahyani, and Rahmi Pratiwi, "Islamic Integration and Tolerance in Community Behaviour; Multiculturalism Model in The Rejang Lebong District," Khatulistiwa 9, no. 1 (May 19, 2019): 1529, https://doi.org/10.24260/khatulistiwa.v9i1.1269.

4 Muhammad Priyatna, "Pendidikan Karakter Berbasis Kearifan Lokal," Edukasi Islami: Jurnal Pendidikan Islam 5, no. 10 (October 25, 2017), https://doi.org/10.30868/ei.v5i10.6. 
merupakan jamak kata "buddhi" akal budi5. Jadi kebudayaan memberikan pesan kepada masyarakat untuk menjunjung tinggi budi pekerti dan akal dalam setiap perilaku. $\mathrm{Ki} \mathrm{Hajar}$ Dewantara menjelaskan bahwa budi manusia merupakan jerih payah manusia yang pengaruhi oleh kekuatan yang kuat yaitu alam dan masa di mana seseorang dapat bertahan hidup di tengah gelombang persoalan kehidupan yang berujung pada kedamaian ${ }^{6}$. Kebudayaan merupakan kebiasaan manusia untuk menyampaikan pesan kepada sang Pencipta sebagai wujud syukur sehingga secara tidak disadari budaya tadi menanamkan nilai-nilai edukatif berupa budi pekerti yang luhur.

Secara komseptual, istilah kebudayaan juga bermakna sebagai seluruh sistem gagasan pikiran, perasaan dan tindakan yang menghasilkan sebuah karya yang dapat dirasakan manfaatnya di tengah-tengah masyarakat bahkan essensi dari budaya tersebut dijadikan sebagai media pembelajaran bagi anak bangsa di kemudian hari ${ }^{7}$. A rtikanya budaya merupakan aktivitas manusia sejak lama dan sampai saat ini hal tersebut masih terjada, terpelihara bahkan dilaksanakan sebagai landasan hukum sosial kemasyarakatan dan dijadikan sebuah pendidikan dalam kehidupan.

Tradisi dilihat dari sudut pandang pendidikan memiliki arti yang sangat banyak. Di mana tradisi sendiri merupakan

5 Tuti Andriani, "Revitalisasi Naskah Syair: Sebuah Solusi dalam Pengembangan Kreativitas Mahasiswa Untuk Mencintai Budaya Lokal," Sosial Budaya 11, no. 1 (January 5, 2015): 91-103, https://doi.org/10.24014/sb.v11i1.828; Nasrul Amin, Feri Siswanto, and Lukman Hakim, "Membangun Budaya Mutu yang Unggul Dalam Organisasi lembaga Pendidikan Islam," AL-TANZIM: Jurnal Manajemen Pendidikan Islam 2, no. 1 (May 14, 2018): 94-106, https://doi.org/10.33650/altanzim.v2i1.308.

${ }^{6}$ Rohmatun Nurul Hidayah, "Pendidikan Anak Usia Dini Perspektif Ki Hajar Dewantara," Al-Mabsut: Jurnal Studi Islam dan Sosial 9, no. 2 (September 1, 2015): 249-58; Mutiara Magta, "Konsep Pendidikan Ki Hajar Dewantara Pada Anak Usia Dini," Jurnal Pendidikan Usia Dini 7, no. 2 (November 1, 2013): 221-32.

${ }^{7}$ Muh Isnanto, "Gagasan Dan Pemikiran Muhammadiyah Tentang Kaderisasi Ulama (Studi Kasus Tentang Ulama Di Muhammadiyah)," Aplikasia: Jurnal Aplikasi Ilmu-Ilmu Agama 17, no. 2 (February 12, 2018): 95-108, https://doi.org/10.14421/aplikasia.v17i2.1380. 
suatu wadah dalam penyampaian ilmu pendidikan. Karena dalam teori empirisme yang menganggap pendidikan itu dipengaruhi oleh lingkungan anak sendiri ${ }^{8}$. Oleh karena itu, pendidikan tidak hanya terfokus pada keluarga, namun nilai pendidikan juga bisa didapat dari masyarakat ${ }^{9}$. Teori tersebut dapat diketahui bahwa didalam ilmu pendidikan tidak hanya teori saja yang disampaikan melainkan berupa aspek sifat atau contoh perilaku dan keterampilan yang biasanya dapat juga diperoleh dari lingkungan masyarakat, salah satunya adalah melalui tradisi tersebut.

Tradisi dalam dunia pendidikan pastinya ada sesuatu yang penting terkandung didalam tradisi tersebut yang dapat digunakan sebagai media atau materi untuk memberikan nilai pendidikan bagi manusia, yang mana terdapatnya nilai-nilai itu yang membuat tradisi tersebut tidak luntur oleh perkembangan zaman. Karena segala sesuatu yang bernilai pasti akan mudah diterima oleh masyarakat dan mudah juga dalam pelestarian dan perkembanganya. Seperti tradisi Merti Deso ini, didalamnya ada makna-makna yang dikandung secara tersirat sehingga upacara ini masih bertahan sampai sekarang.

M asa Ialu dibagian bumi sebelah selatan, tepatnya di wilayah Bantul yang dulu masih berbentuk kadipaten, di sana ada sebuah tradisi luhur warisan dari nenek moyang dengan nama "merti dusun". Pada perkembangannya setelah kerajaan Hindu dan Budha mulai runtuh dan kawasan nusantara berganti dengan hadirnya kerajaan-kerajaan Islam, budaya warisan tersebut mulai di akulturasikan dengan niali Islami, banyak

${ }^{8}$ Idi Warsah, "Interkoneksi Pemikiran Al-Ghazāli Dan Sigmund Freud Tentang Potensi Manusia," Kontekstualita 32, no. 01 (January 26, 2018), http://ejournal.lp2m.uinjambi.ac.id/ojp/index.php/Kontekstualita/article/view/30.

9 Idi Warsah, Pendidikan Islam dalam Keluarga: Studi Psikologis dan Sosiologis Masyarakat Multi Agama Desa Suro Bali (Tunas Gemilang Press, 2020); Idi Warsah, "Pendidikan Keluarga Muslim di Tengah Masyarakat Multi Agama: Antara Sikap Keagamaan Dan Toleransi (Studi di Desa Suro Bali Kepahiang-Bengkulu)," Edukasia: Jurnal Penelitian Pendidikan Islam 13, no. 1 (July 25, 2018): 1-24, https://doi.org/10.21043/edukasia.v13i1.2784. 
tokoh yang sudah melakukan hal ini10. Sultan A gung adalah seorang salah satu raja Mataram yang bias dikatakan berjasa dalam melakukan modifikasi terhadap budaya ini, pada masa pemerintahannya beliau secara langsung turun kelapangan guna memberitahukan atau lebih tepatnya bertitah agar budaya ini dijadikan budaya yang harus dilestarikan sejagad mataram pada saat itu, namun ada hal lain dibalik itu, yaitu dengan dimasukannya nilai islami lewat para "pelaku" utama tradisi merti dusun ini11.

Sewaktu Islam masuk ketanah Jawa, masyarakat telah memiliki kebudayaan yang mengandung nilai yang bersumber pada kepercayaan animisme, dinamisme dari ajaran Hindu dan Budha12. Dengan masuknya Islam, maka pada waktu selanjutnya terjadi perpaduan antara unsur-unsur pra Hindu, Hindu-Budha dan Islam. Dengan datangnya agama Hindu dan Islam, maka kebudayaan Jawa kemudian menyerap unsur budaya-budaya tersebut sehingga menyatulah unsur pra Hindu, Hindu-J awa dan Islam dalam budaya J awa tersebut.

Jadi nilai budaya J awa yang telah terpadu dengan Islam itulah yang kemudian disebut budaya Jawa-Islam. Paling tidak ada dua faktor yang mendorong terjadinya perpaduan nilai-nilai

10 Annisa Ayu Setyawati, "Partisipasi Masyarakat dalam Upacara Merti Dusun (Studi Upacara Merti Dusun di Dusun Mantup, Desa Baturetno, Kecamatan Banguntapan, Kabupaten Bantul)," E-Societas 5, no. 5 (October 12 , 2016),

http://journal.student.uny.ac.id/ojs/ojs/index.php/societas/article/view/4001;

Destha Titi Raharjana and Pade Made Kutanegara, "Pemberdayaan Masyarakat di Kawasan Cagar Budaya," JURNAL TATA KELOLA SENI 5, no. 1 (August 5, 2019): 50-65, https://doi.org/10.24821/jtks.v5i1.3145.

11 Raharjana and Kutanegara, "Pemberdayaan Masyarakat di Kawasan Cagar Budaya.”

${ }^{12}$ Sumper Mulia Harahap, "Islam dan Budaya Lokal Studi terhadap Pemahaman, Keyakinan, dan Praktik Keberagamaan Masyarakat Batak Angkola di Padangsidimpuan Perspektif Antropologi," TOLERANSI: Media Ilmiah Komunikasi Umat Beragama 7, no. 2 (February 10, 2016): 154-176176, https://doi.org/10.24014/trs.v7i2.1428; Samidi Khalim, "SALAT DALAM TRADISI ISLAM KEJAWEN," Sabda: Jurnal Kajian Kebudayaan 6, no. 1 (April 1, 2011): 1-11, https://doi.org/10.14710/sabda.6.1.1-11; Muhammad Ali Mustofa Kamal, "Interelasi Nilai Jawa dan Islam dalam Berbagai Aspek Kehidupan," KALAM 10, no. 1 (June 30, 2016): 19-42, https://doi.org/10.24042/klm.v10i1.18. 
budaya Jawa dan Islam tersebut, yaitu pertama, secara alamiah sifat dari budaya itu pada hakekatnya terbuka untuk menerima unsur budaya lain, dan kedua terjadinya interaksi manusia yang satu dengan lainnya memungkinkan bertemunya unsur-unsur budaya yang ada dan saling mempengaruhi ${ }^{13}$.

M asyarakat J awa merupakan satu kesatuan masyarakat yang diikat oleh norma-norma hidup karena sejarah, tradisi maupun agama. Selain itu, masyarakat Jawa juga terkenal sebagai masyarakat yang memiliki banyak ragam variasi tradisi atau adat ${ }^{14}$. Tradisi-tradisi tersebut dikategorikan menjadi beberapa macam, seperti tradisi dalam acara perkawinan, tradisi dalam acara kelahiran, kemudian dilanjutkan tradisi dalam kematian. Selain itu ada tradisi yang berhubungan dengan bumi lestari ${ }^{15}$. Tradisi-tradisi tersebut lebih umum disebut upacara slametan siklus hidup dan upacara hari besar Islam, serta tradisi bersih desa. Tradisi-tradisi tersebut setiap kategori acaranya memiliki susunan ritual tersendiri didalamnya, seperti pada tradisi perkawinan ada namanya lamaran, pingitan dan lain-lain.

Selain sifat dasar budaya yang terbuka, maka terjadinya perpaduan nilai budaya Jawa Islam tidak terlepas dari faktor pendorong kedua, yaitu sikap toleran para Walisongo dalam menyampaikan ajaran Islam ditengah masyarakat Jawa yang telah memiliki keyakinan pra Islam yang sinkretis itu ${ }^{16}$. Dengan metode manut ilining banyu para wali membiarkan adat istiadat Jawa tetap hidup tetapi diberi warna keislaman, seperti upacara

13 Salman Faris, "Islam dan Budaya Lokal (Studi Atas Tradisi Keislaman Masyarakat Jawa)," THAQAFIYYAT: Jurnal Bahasa, Peradaban Dan Informasi Islam 15, no. 1 (February 6, 2016): 74-90.

14 Arini Sofia, "Perubahan Bentuk Tari Penyajian Tari Bedana Bandar Lampung," Greget: Jurnal Pengetahuan Dan Penciptaan Tari 13, no. 1 (2014), https://doi.org/10.33153/grt.v13i1.531; Muhammad Husni and Tiarma Rita Siregar, Perhiasan Tradisional Indonesia (Direktorat Jenderal Kebudayaan, 2000).

15 Restu Hasnul Zamzami, "Pesan Dakwah Dalam Tradisi Sedekah Bumi Di Dusun Sabet Desa Sumberejo Kecamatan Balong Kabupaten Ponorogo" (diploma, IAIN PONOROGO, 2020), http://etheses.iainponorogo.ac.id/9849/.

16 faris, "Islam dan Budaya Lokal (Studi atas Tradisi Keislaman Masyarakat Jawa)." 
sesajen diganti kenduri/selametan. A cara sesaji dulu disertai mantra, kemudian para wali menggantinya dengan slametan yang disertai kalimah thoyyibah ${ }^{17}$.

Salah satu jenis kebudayaan yang akan dibahas pada studi adalah "Tradisi M erti Deso". Tradisi ini sampai sekarang masih dilaksanakan di berbagai wilayah yang notabene masyarakat J awa dan meyakini kejawen, salah satunya di Desa IV Suku Menanti Kecamatan Sindang Dataran Kabupaten Rejang Lebong. M asyarakat Desa tersebut masih memegang adat dan tradisi "Islam kejawen" dari dulu hingga sekarang yaitu tradisi Sedekah Bumi atau dalam bahasa Jawa juga disebut dengan istilah Merti Deso ${ }^{18}$.

Tradisi Merti Deso tersebut diadakan oleh masyarakat Desa IV Suku M enanti setahun sekali pada bulan Suro, akan tetapi pada pelaksanaanya tidak dipastikan tanggal dalam adat tersebut, pelaksanaanya dilakukan pada Sabtu legi pada bulan Suro karena hari Sabtu dipercaya sebagai hari bumi. M erti Deso merupakan upacara adat masyarakat Jawa untuk menunjukkan rasa syukur manusia kepada Tuhan $\mathrm{Y}$ ang $\mathrm{M}$ aha Esa atas rezeki yang telah diberikan melalui bumi (tanah) berupa berbagai macam hasil.

Membahas tentang tradisi ini tentu tidak dapat melepaskan dari profil desa yang terletak di Kecamatan Sindang Dataran. Kecamatan ini merupakan salah satu daerah penghasil kopi di kabupaten Rejang Lebong yang luas wilayahnya $\pm 6.218 \mathrm{Ha}$, terdiri dari desa Air Rusa, Bengko, IV Suku Menanti, Talang Belitar, Sinar Gunung, Warung Pojok. Desa IV Suku M enanti sendiri sebagian besar masyarakatnya merupakan petani kopi dan sayur yang menggantungkan kehidupannya dengan hasil bumi. Dengan tekstur tanah organosol (tanah gambut) yang berada di bawah kaki bukit kaba

17 Sunaryadi Maharsiwara, "Moslem In The Javanese Culture Pluralism And The Palace Art Performance," Jurnal Humaniora 18, no. 3 (2006): 226-35, https://doi.org/10.22146/jh.v18i3.878.

18 Endarwati Kristiyani and Sri Suwartiningsih, "Makna Ritual Dalam Aliran Musik Band Siramandalem Legion (Studi Komunitas Blackmetal Di Kabupaten Boyolali)," Cakrawala 3, no. 1 (2014), https://ejournal.uksw.edu/cakrawala/article/view/69. 
sehingga menjadikan tanaman dan tumbuhan tumbuh subur, sehingga desa IV Suku M enanti mayoritas penduduknya adalah petani.

Jadi tradisi Merti Deso memiliki maksud untuk menumbuhkan kerukunan antar masyarakat yang berbeda agama, status social dan Iain-lain. Tradisi ini juga dijadikan media pembelajaran bagi generasi muda agar tidak lupa akan sejarah budaya Jawa, khususnya budaya yang ada di Desa. Tradisi Merti Deso juga bertujuan sebagai sarana silaturrahim antar warga, saudara, dan teman. A cara ini bertujuan agar Desa menjadi tenteram, bersih, terib, teratur, indah, dan nyaman sehingga tetap terjaga ketahanan dan kekokohan masyarakat.

Berdasarkan uraian di atas, maka penilitian ini akan meninjau nilai-nalai pendidikan yang ingin disampaikan oleh tradisi Merti Deso yang merupakan budaya masyarakat Jawa yang memiliki ciri khas tersendiri dari sudut pandang Pendidikan Islam. A pakah tradisi ini mengandung nilai-nilai yang bisa dilestarikan dan sejalan dengan pendidikan Islam, ataukah justru dalam tradisi tersebut bertentangan dengan nilainilai Islam.

\section{M etode Penelitian}

Jenis penelitian yang digunakan dalam penelitian ini adalah penelitian deskriptif dengan menggunakan pendekatan kualitatif. Penelitian diskriptif artinya penelitian yang dilakukan untuk menggambarkan atau menjelaskan secara sistematis, faktual, akurat mengenai fakta tentang pelaksanaan tradisi Merti Deso di Desa Desa IV Suku Menanti Kecamatan Sindang Dataran, Rejang Lebong, Bengkulu. Dengan kata lain dalam penelitian kualitatif itu peneliti hendak menggambarkan suatu fenomena atau sifat tertentu, dan digambarkan serta dilukiskan apa adanya ${ }^{19}$.

Subjek dalam penelitian adalah guru, ustad, kepala desa/lurah, tokoh adat, tokoh masyarakat, tokoh agama dan masyarakat desa IV Suku M enanti. Selain itu data juga didapat dari observasi dalam kegiatan Merti Deso pada waktu prosesi

19 Wina Sanjaya, "Penelitian Pendidikan Jenis, Metode Dan Prosedur,” Jakarta: Kencana Prenada Media Group, 2013. 
acara adat itu berlangsung, yaitu pada 28 September 2019 yang bertepatan pada hari sabtu legi di bulan Suro (M uharram) di desa IV Suku Menanti di kediaman bapak Sauri untuk mendapatkan data primer ${ }^{20}$. M etode lain yang digunakan untuk memperoleh data adalah wawancara dengan para narasumber untuk mendapatkan informasi tentang nilai-nilai yang terkandung dalam tradisi tersebut ${ }^{21}$. Waktu pelaksanaan penelitia dilaksanakan kurang lebih satu bulan. Kemudian setelah data terkumpul dilakukan pemilihan data untuk disajikan dalam hasil penelitian dan dianalisis dalam pembahasan selanjutnya diperoleh simpulan sebagai jawaban permasalahan tentang Nilai-Nilai Pendidikan Islam dalam Tradisi Merti Deso pada masyarakat Desa IV Suku Menanti K ecamatan Sindang Dataran K abupaten R ejang L ebong ${ }^{22 .}$

\section{PEMBAHASAN}

Paparan hasil penelitian yang didapatkan di lapangan tentang makna dan Nilai-Nilai Pendidikan Islam dalam Tradisi M erti Deso pada masyarakat desa IV Suku M enanti Kecamatan Sindang Dataran K abupaten R ejang lebong.

Gambaran Pelaksanaan Tradisi M erti Deso

Berdasarkan wawancara dengan bapak Sauri selaku sohibul hajat dalam pelaksanaan upacara M erti Deso di desa IV Suku M enanti tahun 2019:

"A cara merti deso biasanya dimulai dengan bersihbersih lingkungan yang dilaksanakan oleh semua warga, dilanjutkan kerja bakti atau gotong royong untuk membenahi tempat-tempat umum yang ada di dusun, kemudian selametan diiringi dengan tahlilan, kemudian makan bersama, yang terakhir adalah pentas atau

20 Karen Jiggins Colorafi and Bronwynne Evans, "Qualitative Descriptive Methods in Health Science Research," HERD: Health Environments Research \& Design Journal 9, no. 4 (2016): 16-25.

${ }^{21}$ Kathryn Roulston, "Analysing Interviews," The SAGE Handbook of Qualitative Data Analysis, 2014, 297-312.

22 Matthew B. Miles, M. A. Huberman, and Johnny Saldana, "Drawing and Verifying Conclusions. Qualitative Data Analysis: A Methods Sourcebook," 2014. 
pagelaran, seperti wayangan. Sebelum acara pagelaran dimulai pada malam satu suro, masyarakat yang mempercayai tradisi Merti Deso ini menyuguh kan sesajen di setiap tempat yang di anggap keramat. Hal ini di maksudkan untuk menghormati para arwah leluhur. Kemudian di malam 10 suro sebagian masyarakat yang melakuakan puasa mutih melakukan ritual telasan yang berarti selesai dalam pelaksanaan puasa, dan kegiatan ini bermakna bahwa suri tauladan kita nabi muhammad mengakhiri atau pulang dari peperangan. A cara yang menjadi puncak kegiatan adalah wayangan ${ }^{23 " .}$

Tradisi wayang adalah salah satu komponen kebudayaan Jawa yang paling kompleks dan canggih. K ebanyakan muslim kejawen menganggap wayang bisa mewujudkan hakikat kebenaran filosofis dan etika. Selain itu, wayang bisa lebih jernih mendefinisikan, dibandingkan hal apapun, apa artinya menjadi orang Jawa. Tradisi wayangan dilaksanakan sebagai bentuk kesenian yang harus dilestarikan oleh generasi muda, agar kesenian-kesenian yang ada di Indonesia tidak hilang begitu saja. Wayangan memberikan makna yang bersifat positif bagi masyarakat, karena nilai yang terkandung dalam pagelaran wayang memiliki nilai-nilai pendidikan yang berupa perilaku dan sikap baik yang dimiliki para tokoh wayang.

Gambaran tentang tata cara pelaksanaan tradisi Merti Deso, bapak Suhartoyo selaku kepala dusun III di desa Bengko yang mengikuti upacara tersebut menyatakan bahwa tata cara pelaksanaan dibagi menjadi dua tahap, yaitu tahap persiapan dan tahap pelaksanaan upacara:

Pertama, Tahap persiapan masyarakat beserta pamong desa melakukan rapat menentukan waktu dan lokasi pelaksanaan upacara tahunan tradisi Merti Deso. Waktu pelaksanaan Merti Deso adalah bulan Muharram atau dalam kalender jawa yaitu bulan Suro, maka masyarakat desa IV Suku $M$ enanti menyebutnya dengan istilah Suroan. Dalam penelitian ini, pelaksanaan upacara tradisi M erti Deso dilaksanakan yaitu pada 28 september yang bertepatan pada hari sabtu legi di

${ }^{23}$ Wawancara dengan Sauri, tanggal 12 Oktober 2019. 
bulan Suro (M uharram) di desa IV suku M enanti di kediaman bapak Sauri. Masyarakat wajib membayar iuran berdasarkan pendapatan setiap bulan. Dana desa serta hasil iuran masyarakat yang terkumpul dipergunakan untuk membiayai pelaksanaan tradisi Merti Deso atau atau suroan di desa IV Suku M enanti. Dana tersebut dikumpulkan paling lambat 2 hari sebelum prosesi Merti Deso berlangsung. Kedua, tahap pelaksanaan, dalam tahap pelaksanaan terdapat beberapa prosesi, diantaranya adalah: 1) Tabligh akbar, pengajian dilaksanakan di kediaman bapak Sauri, sehari sebelum upacara tradisi Merti Deso berlangsung; 2) Perlombaan seputar keislaman untuk tingkat anak anak, dilaksanakan agar dapat menjadi generasi penerus yang beriman dan bertaqwa kepada Tuhan yang Maha Esa serta memiliki rasa tanggung jawab besar; 3) Selamatan atau kenduri desa, dipusatkan di masjid dan diikuti oleh masyarakat desa IV Suku Menanti bertujuan mendoakan desa IV Suku Menanti dari segala macam gangguan; 4) Pertunjukan wayang kulit, lakon (tokoh wayang) yang di ambil setiap tahunnya berbeda-beda. Lakon yang di ambil adalah "Lahire Parikesit" pengambilan lakon tersebut dimaksudkan agar desa IV Suku Menanti mendapat hikmah serta memulai hidup baru sebagaimana diceritakan dalam lakon wayang. Setiap desa atau daerah tertentu pasti mempunyai kebudayaan. Namun kebudayaan tersebut bisa sama dan bisa pula berbeda, seperti halnya dengan desa IV Suku M enanti kebudayaan atau seni pertunjukan rakyat adalah wayang. Upacara merti deso atau bersih desa merupakan sebuah fenomena yang terjadi ditengah masyarakat, dan mungkin fenomena ini tidak terjadi dalam satu daerah saja, melainkan ada kesamaan dengan daerah-daerah lain di Indonesia yang merupakan N egara dengan beribu kebudayaan dan ragamnya ${ }^{24}$.

M emperkuat penjelasan di atas, Y ayuk Ernawati selaku masyarakat yang aktif dalam organisasi desa menyatakan bahwa: 
"Upacara Merti Deso di desa IV Suku Menanti ini dilakukan setelah selesai panen raya, yaitu waktu panen bagi semua petani palawija dan sebagainya pada saat itu. Beliau menjelaskan bahwa fenomena atau kegiatan ini sudah menjadi sebuah tradisi dan kebudayaan yang dilakukan setahun sekali, runtutan acaranya adalah jika masa panen sudah tiba, maka di sana akan diadakan perkumpulan yang mana akan dibahas mengenai acara tahunan itu. Selanjutnya diperkumpulan itu akan dimusyawarahkan bagaimana baiknya dan seyogyanya upacara tahunan ini benar-benar menjadi pesta rakyat. Pada perkumpulan itu dihadiri oleh kepala desa, perangkat dari setiap desa dan para sesepuhnya. Perlu diketahui upacara Merti Deso ini dilakukan sekecamatan jadi ini merupakan kegiatan yang didukung oleh semua desa se-kecamatan Sindang Dataran"25.

Berdasarkan pernyataan di atas, diperoleh gambaran ketika ditinjau dari kacamata tujuan dan tata cara pelaksanaan bahwa tradisi Merti Deso masyarakat desa IV Suku M enanti sama sekali tidak melenceng dari ajaran Islam atau dari aturanaturan/ketentuan-ketentuan yang telah diperintahkan oleh A llah SWT. M asyarakat tetap menjaga apa yang telah di larang oleh A llah. K arena masyarakat desa IV Suku M enanti sebagian besar telah mengetahui ajaran-ajaran yang telah ditetatapkan Allah SWT. Walaupun dengan diadakan kegiatan Merti Deso masyarakat tidak melupakan syari' at sebagai orang Islam.

Makna Tradisi Merti Deso bagi masyarakat Deso IV Suku M enanti

M akna dari M erti Deso yang di lakukan di desa IV Suku Menanti ini menurut Ustadz Budiono selaku tokoh agama di desa tersebut yaitu:

"Ungkapan rasa syukur, ungkapan pengharapan, dan ungkapan persaudaraan. Rasa syukur itu ditujukan kepada Tuhan yang Maha Esa yang telah memberikan begitu banyak limpahan rejeki selama tahun 2019. Ungkapan pengharapan yang tersirat dalam kegiatan

${ }^{25}$ Wawancara dengan Yayuk Ernawati, tanggal 15 Oktober 2019. 
Budaya ini adalaha perwujudan syukur dan doa dengan harapan agar diberikan kebaikan di masa mendatang dan dijauhkan hal-hal buruk yang masih menaungi masyarakat Sindang Dataran ini. Lalu ungkapan persaudaraan yang dimaksudkan oleh masyarakat setempat terwujud pada semangat gotong royong, saling toleran, guyup rukun antar masyarakat dusun IV Suku M enanti sendiri" 26.

Prosesi terakhir/penghujung acara, sedekah yang diwujudkan dalam bentuk sesajian dan beragam hidangan yang akan dibagikan kepada seluruh warga desa serta siapa pun yang hadir. Kadang prosesi pembagian sedekah ini sengaja dilakukan dengan cara diperebutkan, sehingga menghadirkan atraksi yang begitu meriah27.

Lalu pada malam harinya diadakan tontonan wayang untuk dinikmati warga IV Suku Menanti dan sekitarnya, bertempat di kediaman perangkat desa setempat (bapak Sauri) selama satu malam suntuk ${ }^{28}$. A cara ini bukan hanya sebagai simbolisasi tradisi, melainkan pengenalan budaya kepada masyarakat dan anak muda. Sehingga kebudayaan ini tetap lestari dan tetap menjadi bagian dari kebudayaan nasional. Selain untuk pengenalan, acara Merti Deso seperti ini juga bermanfaat bagi warga itu sendiri, dengan adanya wayangan maka akan ada masyarakat dusun sekitar yang ikut menonton, sehingga bisa membuka lapangan bisnis untuk warga itu sendiri.

Bapak Ponijan selaku sesepuh yang hadir daalam pelaksanaan kegiatan menjelaskan bahwa

"T ujuan diselenggarakannya tradisi Merti Deso adalah sebagai pelestarian budaya serta wujud rasa syukur masyarakat terhadap Tuhan $Y$ ang $M$ aha Esa yang telah memberikan keselamatan, kesehatan juga rejeki yang berlimpah sehingga masyarakat bisa hidup tentram dan damai. Selain itu juga untuk melestarikan kesenian dan

${ }^{26}$ Wawancara dengan Budiono, selaku Tokoh Agama, 20 Oktober 2019.

${ }^{27}$ Observasi, 28 September 2019

${ }^{28}$ Observasi, 28 September 2019 
kebudayaan yang ada di desa IV Suku Menanti. Kegiatan ini sangat sejalan dengan program Dinas K ebudayaan untuk selalu menjaga nilai-nilai tradisi dan budaya lokal yang ada, tuturnya" ${ }^{29}$

Selain menjadi perwujudan rasa syukur, upacara M erti Deso sering kali juga terkait dengan ritual penghormatan kepada leluhur, sehingga menghadirkan berbagai ritual simbolik terkait dengan tokoh dan riwayat yang diyakini menjadi cikal bakal keberadaannya. Semuanya dilakukan dengan tetap memanjatkan doa dan permohonan kepada $Y$ ang M aha K uasa demi keselamatan, ketentraman, kesejahteraan dan keselarasan hidup seluruh warga desa. Silaturahmi, guyub, rukun, gotong royong, kebersamaan, keakraban, tepa selira dan harmonis adalah sebagian dari sederetan kosakata yang begitu tepat dan saling menjalin makna saat menggambarkan bagaimana suasana yang terpancar dari berlangsungnya tradisi M erti Deso.

Banyak sekali makna yang terkandung dalam upacara ini, penjelasan sebelumnya sudah diterangkan bahwa upacara tahunan ini merupakan sebuah wujud syukur kepada tuhan atas segala apa yang diberi di dunia yaitu berupa rezeki, umur, dan alam sebagai sumber kehidupan. Selanjutnya jika dilihat dari segi sosial kemasyarakatan, maka kegiatan semacam ini bisa saling mengeratkan rasa kesatuan diantara warga sekecamatan Sindang Dataran. Dari segi ekonomi kegiatan ini juga bisa menghasilkan nilai rupiah dengan menarik perhatian para wisatawan. A da lagi dari sisi kebudayaan, hal seperti ini jelas bisa melestarikan kebudayaan nenek moyang. Dengan kata lain pada upacara Merti Deso ini ditujukan untuk rakyat atau semua warga agar dalam dirinya tumbuh rasa saling memiliki dan menjaga lingkungan dan alam, serta menghargai sesama dalam kehidupan di dunia, serta mengajak pada kebaikan dengan menyelipkan nilai Islami dalam kegiatan tahunan ini. Nilai-nilai Pendidikan Islam Dalam Tradisi M erti Deso

Nilai-nilai Pendidikan yang ditemukan baik dari informan maupun hasil pengamata dalam tradisi M erti Deso di

${ }^{29}$ Wawancara dengan Ponijan, 17 Oktober 2019. 
desa IV Suku M enanti K ecamatan Sindang Dataran Kabupaten Rejang L ebong adalah sebagai berikut:

1) Nilai Religius

M uatan dalam tradisi M erti Deso terdapat dua nilai ibadah yaitu: 1) Pembacaan ayat Al-Qur'an, dzikir, shalawat, dan do'a pada saat inti acara sedekah bumi. Hal ini bertujuan agar masyarakat terbiasa dan mampu mengingat dan menghafal ayat AI-Qur'an, dzikir, shalawat dan do'a. Kemampuan masyarakat dalam membaca A I-Qur'an sangat berpengaruh terhadap kemampuannya dalam melaksanakan shalat fardhu. Sebelum mulai makan, warga masyarakat desa IV Suku Menanti membaca doa sebelum makan secara bersama-sama dipimpin oleh U stadz. Hal tersebut bertujuan agar masyarakat terbiasa membaca doa sebelum makan sebagai ungkapan syukur atas nikmat yang diberikan Allah SWT. 2) Nilai Religius pada prosesi kegiatan Merti Deso terdapat nilai-nilai hubungan antara manusia dan Tuhan. Adanya sesaji yang akand bagikan kepada seluruh masyarakat yang hadir adalah perwujudan rasa syukur pada Tuhan atas nikmat yang diberikan. Merti Deso juga mengingkatkan hubungan manusia dengan para leluhur. M anusia juga diingatkan dalam prosesi M erti Deso bahwa sehebat apapun manusia pasti akan mengalami sebuah kematian.

2) Nilai Sosial

Tradisi Merti Deso banyak melibatkan warga. Warga dengan bergotong royong mempersiapkan, melaksanakan dan setelah selesai kegiatan Merti Deso bersama-sama membersihkan tempat yang digunakan. Dengan bergotong royong warga melestarikan hubungan kebersamaan sebagai perwujudan nilai sosial dalam masyarakat. Dalam tradisi ini ditemukan nilai-nilai kebersamaan untuk saling membantu antar warga yang satu dengan yang lainnya. Ini merupakan salah satu bukti bahwa kehiupan masyarakat di desa IV Suku Menanti masih terdapat budaya saling membantu (gotong royong).

Dengan adanya rasa saling membantu secara tidak langsung tradisi Merti Deso ini dapat menjaga kerukunan 
antar warga. Hal ini merupakan bentuk kecintaan masyarakat terhadap lingkungan. Dalam tradisi yang sudah mendarah daging dalam masyarakat IV Suku Menanti ini dapat kita jadikan bahan renungan hidup terutama dalam hal saling membantu antar sesama. Karena di zaman modern seperti saat ini sangat sulit kita temukan orangorang yang mau untuk saling bantu, terkecuali dengan adanya uang.

Bahkan terjalin hubungan yang erat antara manusia dengan manusia lain ditunjukan dengan pada saat makan bersama para warga saling bertukar lauk pauk yang mereka bawa dari rumah. Hal tersebut memberikan pemahaman pada masyarakat untuk saling peduli dengan tetangganya, tidak mempunyai sifat kikir dan pelit.

3) Nilai Ekonomi

Pelaksanaan M erti Deso yang berisi mujahadah, pertunjukan tayub, kirab, wayang kulit, mengundang masyarakat berkumpul. Pertunjukan banyak disaksikan baik oleh orang tua maupun anak-anak. Berkumpulnya anak-anak dan orang tua memberikan peluang kepada yang ingin berjualan untuk menambah penghasilan. Para pedagang biasanya terdiri dari penjual makanan, kerajinan dan lain-lain.

\section{A nalisa}

Tradisi merupakan bentuk ritual keagamaan yang tidak hanya sebagai pewarisan semata dari leluhur. Namun, tradisi harus ada tujuannya yaitu untuk menanamkan nilai-nilai atau norma-norma pendidikan Islam melalui pengulangan hal-hal yang telah ada pada masa lalu. Tradisi dapat disebut juga dengan selamatan yang dihadiri oleh semua warga seperti tradisi Merti Deso. Menurut Khalil dalam Qomariyah menyatakan bahwa "dalam selamatan terungkap nilai-nilai yang dirasakan sangat mendalam oleh orang Jawa, yaitu nilai kebersamaan, persaudaraan, dan kerukunan" 30 .

30 Nurul Qomariyah, "Implementasi Nilai-Nilai Pendidikan Islam dalam Tradisi Merti Dusun untuk Menumbuhkan Kerukunan Umat Beragama (Studi Kasus di Dusun Kedakan Desa Kenalan Kec. Pakis Kab. Magelang” (other, Fakultas Tarbiyah dan Ilmu Keguruan, 2016), http://erepository.perpus.iainsalatiga.ac.id/1126/. 
Nilai tradisi setiap masyarakat merupakan realitas yang multikompleks dan dialektis. Nilai-nilai itu mencerminkan kekhasan masyarakat sekaligus sebagai pengejawantahan nilainilai universal manusia. Nilai-nilai tradisi dapat dipertahankan sejauh di dalam diri mereka terdapat nilai-nilai kemanusiaan. Nilai-nilai tradisi yang tidak lagi mencerminkan nilai-nilai kemanusiaan, maka manusia akan kehilangan martabatnya. Tradisi dapat dijadikan dalam pelaksanaan pendidikan Islam. Penerimaan tradisi ini memiliki beberapa syarat, yaitu tidak bertentangan dengan ketentuan nash pokok, baik A I-Qur' an dan Sunnah, tradisi yang tidak bertentangan dengan akal sehat dan tabiat yang sejahtera, serta tidak mengakibatkan kedurhakaan, kerusakan dan kemunduran ${ }^{31}$.

Nilai-nilai positif yang ada dalam suatu agama banyak diterapkan dalam kebudayaan, seperti nilai kerukunan, kehormatan, dan sosial kemasyarakatan. Oleh karena itu, kebudayaan dan agama yang memiliki hubungan erat antara satu sama lain tidak dapat dipisahkan. A gama memiliki cara pandang tersendiri terhadap kebudayaan, dan kebudayaan juga menjadi peran untuk menyatukan antar warga, bangsa, dan bahasa menjadi satu kesatuan tanpa adanya suatu persel isihan.

Pandangan masyarakat dari segi agama, tradisi Merti Deso dalam pelaksanaannya tetap tertuju pada tuntunan ajaran agama Islam. Sesaji hanyalah sebagai alat pelengkap yang digunakan dalam acara tersebut. sementara pandangan masyarakat dari segi pendidikan, pelaksanaan upacara tradisi Merti Deso di Desa IV Suku Menanti ini, mengandung nilainilai yang mencerminkan cipta, rasa, dan karsa dari manusia pendukung tradisi tersebut, juga merupakan pendidikan terhadap rasa solidaritas, saling tolong-menolong, dan kebersamaan. Tradisi ini mengandung nilai pendidikan yaitu wujud kesatuan dimana dalam pelaksanaan melibatkan banyak orang sehingga terjalin hubungan yang saling membutuhkan untuk kelancaran upacara.

31 Galuh Dwi Purwasih, "Upaya Guru Pendidikan Agama Islam Dalam Menumbuhkan Motivasi Pembelajaran di MI Al-Hikmah Karangrejo dan MI Sunan Ampel Bono," Tadrisuna: Jurnal Pendidikan Islam dan Kajian Keislaman 2, no. 2 (November 13, 2019): 36-49. 
Pandangan masyarakat dari segi kebudayaan, pertunjukan wayang kulit termasuk didalam unsur budaya Jawa. U pacara M erti Deso dilaksanakan untuk merayakan hasil panen padi warga yang melimpah. Setiap desa atau daerah tertentu pasti mempunyai kebudayaan. Namun kebudayaan tersebut bisa sama dan bisa pula berbeda, seperti hal nya dengan desa IV Suku M enanti kebudayaan atau seni pertunjukan rakyat adalah wayang. A jaran-ajaran Jawa mulai dari tradisi, sesaji dan wayangan merupakan bentuk budaya yang terwujud.

Secara umum pandangan masyarakat tentang upacara tradisi Merti Deso adalah upacara ini sebagai media sosial. Maksudnya, tradisi tersebut dipakai sebagai sarana mengutarakan pikiran dan kepentingan yang menjadi hajat hidup orang banyak. Upacara tersebut digunakan untuk mengingat apa yang telah dilakukan leluhurnya pada masa lalu sampai masa sekarang. Selain itu upacara tradisional seperti ini juga menjadi media untuk melakukan kontak sosial di antara warga. Di antara contoh dari kontak sosial tersebut adalah pada saat membuat peralatan dan perlengkapan upacara yang dilakukan secara bersama-sama, memberikan sumbangan demi kelancaran acara tersebut dan melakukan ritual secara bersamasama. Intinya upacara tradisi Merti Deso masih menjaga kelestarian budaya dengan petunjuk dan tuntunan ajaran agama Islam. Nilai-nilai budaya yang terkandung didalamnya sangatlah kuat dan akan dipertahankan sampai kapanpun.

Penerapan nilai-nilai pendidikan Islam dalam tradisi Merti Deso untuk menumbuhkan kerukunan umat beragama dapat dilakukan melalui nilai I'tiqadiyyah, K huluqiyyah dan A maliyyah, yang dapat ditunjukkan dengan cara:

a. W ujud Sukur sebagai nilai religus dan spiritual

W ujud syukur warga dusun IV Suku Menanti merupakan bentuk terimakasih kepada Allah SWT., syukur itu dapat direalisasikan dengan cara bersedekah, karena telah diberi rezeki melimpah yang diwujudkan dalam tradisi merti dusun, yaitu dengan cara saling berbagi makanan kepada warga lain. Orang J awa pun percaya bahwa ketika manusia itu tertimpa musibah atau bencana, mereka tetap berfikiran 
bahwa ada hikmah dibalik musibah tersebut. Disini terbesit bahwa dalam pemikiran orang J awa masih ada rasa syukur.

b. Penanaman Sikap Toleransi antar U mat Beragama sebagai nilai sosial

Sikap toleransi dapat diterapkan dalam berbagai hal, misalnya tidak menjauhi dan melarang orang K risten untuk tinggal bersama di lingkungan warga Islam. Dengan sikap toleransi yang menjadi sebuah prinsip maka akan terbangun kerukunan antar umat beragama, dan mereka sadar bahwa kerukunan beragama dalam masyarakat itu adalah milik bersama yang menjadi tanggung jawab mereka dan harus dijaga. Karena kerukunan antar umat beragama itu bukan hanya kerukunan sementara, namun menjadi kerukunan hakiki yang harus dilandasi dan dijiwai oleh agama masingmasing.

\section{KESIMPULAN}

Berdasarkan hasil analisis data dari penjelasan sebelumnya, peneliti dapat menyimpulkan bahwa hasil penelitian tentang Nilai-Nilai Pendidikan Islam dalam Tradisi Merti Deso di Desa IV Suku Menanti Kecamatan Sindang Dataran Kabupaten Rejang Lebong, yaitu: Pertama, nilai Religius dan spiritual, seperti ungkapan rasa syukur kepada Tuhan yang Maha Esa yang telah memberikan begitu banyak limpahan rejeki selama satu tahun tersebut dan berdoa agar terhindar dari bala dan bencana di masa yang akan datang. $K$ Kedua, nilai Sosial yang buktikan dengan kegiatan M erti Deso berjalan dengan lancar karena jalinan silaturrahim yang kuat dan sikap gotong Royong yang tinggi tanpa membedakan agama dan keyakinan, status social dan lain-lain. Ketiga, Nilai Ekonomi, rangkaian kegiatan dalam Merti Deso banyak membuat warga berkumpul sehungga memberikan peluang usaha bagi warga dan hal ini secara langsung memberikan keuntungan ekonomi bagi warga. 


\section{DAFTAR PUSTAKA}

Amin, Nasrul, Feri Siswanto, and Lukman Hakim. "Membangun Budaya Mutu yang Unggul Dalam Organisasi lembaga Pendidikan Islam." al-Tanzim: Jurnal Manajemen Pendidikan Islam 2, no. 1 (M ay 14, 2018): $\quad$ 94-106. https://doi.org/10.33650/altanzim.v2i1.308.

Andriani, Tuti. "Revitalisasi Naskah Syair: Sebuah Solusi dalam Pengembangan Kreativitas Mahasiswa Untuk Mencintai Budaya Lokal." Sosial Budaya 11, no. 1 (January $\quad 5, \quad$ 2015): https://doi.org/10.24014/sb.v11i1.828.

Colorafi, Karen Jiggins, and Bronwynne Evans. "Qualitative Descriptive Methods in Health Science Research." HERD: Health Environments Research \& Design Journal 9, no. 4 (2016): 16-25.

Faris, Salman. "Islam dan budaya lokal (Studi atas Tradisi Keislaman Masyarakat Jawa)." Thaqafiyyat: Jurnal Bahasa, Peradaban Dan Informasi Islam 15, no. 1 (February 6, 2016): 74-90.

Harahap, Sumper Mulia. "Islam Dan Budaya Lokal Studi terhadap Pemahaman, Keyakinan, dan Praktik Keberagamaan Masyarakat Batak Angkola di Padangsidimpuan Perspektif Antropologi." Toleransi: Media I/miah Komunikasi Umat Beragama 7, no. 2 (February 10, 2016): 154-176-176. https://doi.org/10.24014/trs.v7i2.1428.

Hidayah, Rohmatun Nurul. "Pendidikan Anak Usia Dini Perspektif Ki Hajar Dewantara." Al-Mabsut: Jurnal Studi Islam dan Sosial 9, no. 2 (September 1, 2015): 249-58.

Husni, Muhammad, and Tiarma Rita Siregar. Perhiasan Tradisional Indonesia. Direktorat J enderal Kebudayaan, 2000.

Isnanto, Muh. "Gagasan Dan Pemikiran Muhammadiyah Tentang Kaderisasi Ulama (Studi Kasus Tentang Ulama 
Di M uhammadiyah)." A plikasia: Jurnal A plikasi I/muI/mu Agama 17, no. 2 (February 12, 2018): 95-108. https://doi.org/10.14421/aplikasia.v17i2.1380.

Kamal, M uhammad Ali M ustofa. "Interelasi Nilai Jawa dan Islam dalam B erbagai A spek K ehidupan." Kalam 10, no. 1 (June 30, 2016): 19-42. https://doi.org/10.24042/klm.v10i1.18.

K halim, Samidi. "Salat dalam Tradisi Islam Kejawen." Sabda: Jurnal Kajian Kebudayaan 6, no. 1 (A pril 1, 2011): 1-11. https://doi.org/10.14710/sabda.6.1.1-11.

K ristiyani, Endarwati, and Sri Suwartiningsih. "Makna Ritual Dalam A liran M usik Band Siramandalem Legion (Studi Komunitas Blackmetal Di Kabupaten Boyolali)." Cakrawala 3, no. 1 (2014). https://ejournal.uksw .edu/cakrawala/article/view/69.

M agta, M utiara. "K onsep Pendidikan K i Hajar Dewantara Pada A nak Usia Dini." Jurnal Pendidikan Usia Dini 7, no. 2 (N ovember 1, 2013): 221-32.

Maharsiwara, Sunaryadi. "Moslem In The Javanese Culture Pluralism And The Palace Art Performance." Jurnal Humaniora 18, no. 3 (2006): 226-35. https://doi.org/10.22146/jh.v18i3.878.

Miles, M atthew B., M. A. Huberman, and Johnny Saldana. “Drawing and Verifying Conclusions. Qualitative Data A nalysis: A M ethods Sourcebook," 2014.

Nurhasanah, Nurhasanah. "Faktor-Faktor Penyebab Rendahnya Prestasi Belajar A qidah A khlak Di K elas IV MIS Iqro' Ummat Kecamatan Manggelewa Tahun Pelajaran 2016/2017." al-Furqan 5, no. 1 (A ugust 31, 2016): 1540.

Priyatna, M uhammad. "Pendidikan Karakter Berbasis K earifan Lokal." Edukasi Islami: Jurnal Pendidikan Islam 5, no. 10 (October 25 , 2017). https://doi.org/10.30868/ei.v5i10.6.

Purwasih, Galuh Dwi. "Upaya Guru Pendidikan Agama Islam Dalam M enumbuhkan M otivasi Pembelajaran di MI AlHikmah Karangrejo dan MI Sunan Ampel Bono." 
Tadrisuna: Jurnal Pendidikan Islam dan Kajian Keislaman 2, no. 2 (November 13, 2019): 36- 49.

Puspianto, Alim. "Tantangan Dakwah A ntar Budaya Di Media Massa." An-Nida': Jurnal Komunikasi Dan Penyiaran Islam 6, no. 1 (2017): 25-46.

Q omariyah, Nurul. "Implementasi Nilai-Nilai Pendidikan Islam dalam Tradisi Merti Dusun Untuk Menumbuhkan Kerukunan Umat Beragama (Studi Kasus Di Dusun Kedakan Desa Kenalan Kec. Pakis Kab. Magelang." Other, Fakultas Tarbiyah dan IImu Keguruan, 2016. http://e-repository.perpus.iainsalatiga.ac.id/1126/.

Raharjana, Destha Titi, and Pade Made Kutanegara. "Pemberdayaan Masyarakat di Kawasan Cagar Budaya." Jurnal Tata Kelola Seni 5, no. 1 (August 5, 2019): 50-65. https://doi.org/10.24821/jtks.v5i1.3145.

Roulston, Kathryn. "Analysing Interviews." The SAGE Handbook of Qualitative Data A nalysis, 2014, 297-312.

Sanjaya, Wina. "Penelitian Pendidikan Jenis, Metode Dan Prosedur." Jakarta: Kencana Prenada Media Group, 2013.

Setyawati, Annisa Ayu. "Partisipasi Masyarakat Dalam Upacara Merti Dusun (Studi Upacara Merti Dusun di Dusun Mantup, Desa Baturetno, Kecamatan B anguntapan, K abupaten Bantul)." E-Societas 5, no. 5 (October

http://journal.student.uny.ac.id/ojs/ojs/index.php/societa s/article/view/4001.

Sofia, A rini. "Perubahan Bentuk Tari Penyajian Tari Bedana Bandar Lampung." Greget: Jurnal Pengetahuan Dan Penciptaan Tari 13, no. 1 (2014). https://doi.org/10.33153/grt.v13i1.531.

Wakhyuni, Emi. "Kemampuan M asyarakat dan Budaya A sing dalam Mempertahankan Budaya Lokal Di Kecamatan Datuk Bandar." Jurnal A bdi I/mu 11, no. 1 (2018): 2531.

Warsah, Idi. "Interkoneksi Pemikiran A I-Ghazāli Dan Sigmund Freud Tentang Potensi M anusia." Kontekstualita 32, no. 01 (January 26, 2018). http://e- 
journal.Ip2m.uinjambi.ac.id/ojp/index.php/K ontekstualit a/article/view/30.

- - - . Pendidikan Islam dalam Keluarga: Studi Psikologis dan Sosiologis Masyarakat Multi Agama Desa Suro Bali. Tunas Gemilang Press, 2020.

- - - . "Pendidikan Keluarga M uslim di Tengah M asyarakat Multi A gama: A ntara Sikap K eagamaan dan Toleransi (Studi di Desa Suro Bali Kepahiang-Bengkulu)." Edukasia: Jurnal Penelitian Pendidikan Islam 13, no. 1 (July 25, 2018): 1-24. https://doi.org/10.21043/edukasia.v13i1.2784.

Warsah, Idi, Dewi Cahyani, and Rahmi Pratiwi. "Islamic Integration and Tolerance in Community Behaviour; Multiculturalism Model in The Rejang Lebong District." Khatulistiwa 9, no. 1 (M ay 19, 2019): 15-29. https://doi.org/10.24260/khatulistiwa.v9i1.1269.

Zamzami, Restu Hasnul. "Pesan Dakwah Dalam Tradisi Sedekah Bumi Di Dusun Sabet Desa Sumberejo Kecamatan Balong Kabupaten Ponorogo." Diploma, IAIN Ponorogo, 2020. http://etheses.iainponorogo.ac.id/9849/. 